\title{
LOSS AND PRESERVATION OF CHIMNEY SWIFT HABITAT IN MANITOBA, 2007-2016
}

Robert E.A. Stewart

Sila Consultants

1218 Marchand Road

Howden, MB R5A $1 \mathrm{~J} 6$

sila@highspeedcrow.ca

\section{Timothy F. Poole}

Manitoba Chimney Swift Initiative

Habitat Stewardship and Outreach

Coordinator

Nature Manitoba

401-63 Albert Street

Winnipeg, MB R3B 1G4

\section{Christian Artuso}

Bird Studies Canada, Manitoba Program Manager

Box 24-200 Saulteaux Crescent

Winnipeg, MB R3J 3W3

\section{Barbara E. Stewart}

Sila Consultants

1218 Marchand Road

Howden, MB R5A $1 \mathrm{~J} 6$

sila@highspeedcrow.ca

\section{Introduction}

The Chimney Swift (Chaetura pelagica, Fig. 1) in Canada has been assigned the status of "Threatened" under the Species At Risk Act (SARA). ${ }^{1}$ Manitoba has also listed the Chimney Swift as "Threatened" under The Endangered Species and Ecosystems Act. ${ }^{2}$ SARA lists loss of nesting and roosting habitat (chimneys) as the most significant threat although Fitzgerald et al. suggest chimney habitat in Ontario may not be a limiting factor. ${ }^{3}$

There seem to be few data on the rate at which chimneys suitable for Chimney Swifts are being lost from their environment and whether such losses are limiting or not. Using data collected by volunteer citizenscientists in Manitoba, it is now possible to estimate the annual rate

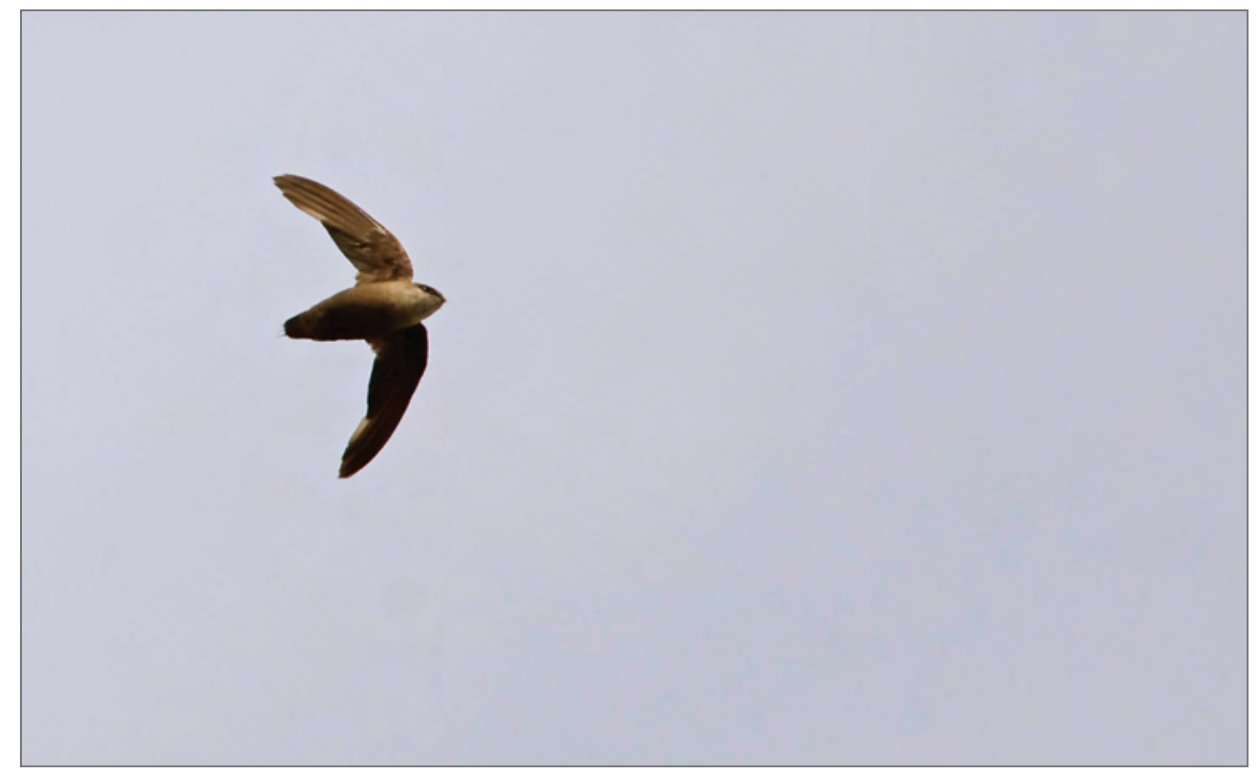

FIGURE 1. A Chimney Swift (Chaetura pelagica) in flight showing the characteristic ovoid body and boomerang-shaped wings. The bristled tail feathers, used for bracing when the bird rests on vertical surfaces, can also be seen. Photo copyright - DM Lavigne, 2015

at which available chimney habitat is being lost in this part of the bird's range. Here we present data on chimney loss in southern Manitoba between the start of the Chimney Swift season (nominally May 1) of 2007 until the start of the season in 2017 (10 years). We also examine the effect of volunteer efforts to reverse habitat losses.

\section{Methods}

The Manitoba Chimney Swift Initiative (MCSI) benefits from a cadre of about 60 volunteers who search for, and identify, potential and active Chimney Swift nest or roost sites. In the decade since 2007, volunteers have collected data on the numbers of birds observed entering the chimneys and, occasionally, data on nesting behaviour and outcome. ${ }^{4,5}$

New sites are often discovered when Chimney Swifts are seen in the air and an effort is made to track them to a chimney in the evening. Others are found by happenstance. One was classified as 'active' because although no entries or exits were recorded, there was evidence of former nesting activity in the chimney cleanout trap. Chimneys were considered to be suitable as Chimney Swift habitat if they were of adequate size ( $\geq 2.5$ bricks square), unlined, accessible (not capped or screened), and in an area where Chimney Swifts have been observed. The 'area where Chimney Swifts have been observed' was a broad criterion. In some smaller rural locations, it meant local residents had reported seeing Chimney Swifts in the air.

Known sites accrued over the years. We assumed in this analysis that if a chimney was seen to be active at any time in the decade, it had been available habitat for the whole decade. For example, if a suitable site was 'discovered' in 2016 it was considered to have been suitable habitat in 2007 and all intervening years. None of the chimneys in the data base was constructed after 2007. 
In 2009, MCSI initiated a Chimney Swift habitat preservation program. This entails entering into agreements with property owners to assist financially with essential chimney repairs in return for a commitment to retain the chimney as available Chimney Swift habitat. It also includes direct education leading to agreements with owners that planned closures will not proceed. MCSI also conducts a public education program and there may be other chimneys that remain open due to the information made available to the public. There are no data on these sites.

\section{Results}

Over 10 monitoring seasons, spring of 2007 to fall of 2016, MCSI volunteers identified 200 potential Chimney Swift sites. The number of observations varied among years (Fig. 2) and by site. Of the 200 chimneys or sites in the MCSI database, nine were not monitored in any year. Another 57 chimneys were monitored with variable effort and there were no observations of Chimney Swifts using them. These two categories of chimneys were grouped and referred to as potential habitat. The remaining 134 active sites were known to house Chimney Swifts at least one year in the 10-year sample by volunteers observing entries or exits.

Over the 10 years of the MCSI database, 29 of the total 200 identified sites were lost (14.5\%). Of sites known to have been used by Chimney Swifts in this period, 19 of 134 (14.2\%) were lost. Losses varied among years (Fig. 3) and averaged $2.9+1.1$ (mean $+1 \mathrm{SE}$ ) chimneys per year $(n=10)$ for potential plus active sites and $1.9+0.6(n=10)$ for active sites only. The timing of habitat loss was not always apparent. Many chimneys were closed between Chimney Swift seasons although some were removed when the birds were still present. Most lost chimneys had been occupied the season before loss or the season of loss (15 of 19). For three of the remaining four sites, MCSI has no occupancy data in the season before destruction. The last chimney was not occupied the year before it was lost but housed a pair the year before that.

The average number of birds that had occupied the chimney immediately prior to it being lost was $2.1+0.4$ ( $n=19$ chimneys) although the average usage for years for which there are data was $4.3+1.1$ ( $n=52$ annual counts at 19 chimneys). The difference arises because the maximum counts at two of the 19 lost sites were 18 and 48 birds (Fig. 4). The average number of birds using the chimney, immediately before the chimney became unavailable, is negatively biased because the parents were feeding young in at least one site when it was demolished.

Data on the type of Chimney

Swift use (nest or roost) are incomplete. However, at 14 of the 19 lost chimneys the maximum recorded count was one or two. More than 10 birds were recorded entering each of two sites which, therefore, were clearly used as roosts (Fig. 4).

Chimneys were lost to three main events. They were capped or lined (16), torn down (nine, including one demolished with the building) or screened (three). One collapsed.

Winnipeg had the largest number of sites ( 120 or $60.0 \%$ of potential plus active sites) of all municipalities monitored and $69.0 \%$ of the total losses. Winnipeg lost 20 potential or active sites (16.5\%). Some smaller communities had higher loss rates of active sites. For example, one of three (occupied annually since 2010) in Carman was lost (33\%); four of 11 in Portage la Prairie (36\%); one of two (occupied every year from 2010 on) sites in Brandon (50\%); and the only active site known in Lorette, found in 2012, was occupied in 2012 and 2013 then lost (100\%). Both the Carman and Brandon sites may have been roosts as well as nest sites; the others appear to have been nest sites only. In larger communities, there may be undiscovered alternate sites but this is less likely in smaller settlements.

Since 2009, MCSI and its partners have assisted with the repair of 11 chimneys (Fig. 5) and reached agreements with owners to

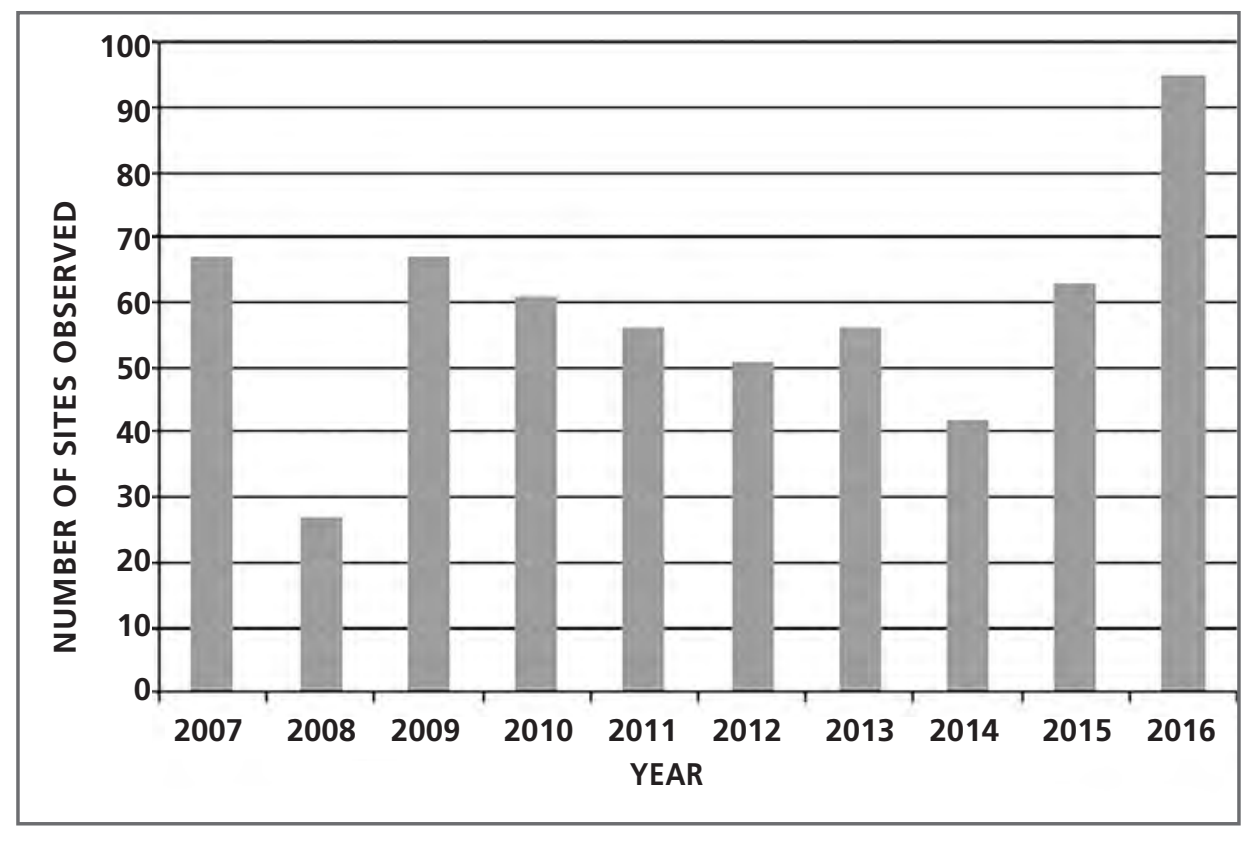

FIGURE 2. Number of chimneys monitored each year since the inception of the Manitoba Chimney Swift Initiative monitoring program. 
abandon plans to close another three chimneys. All 14 sites were known to have had Chimney Swift residents before preservation. Preserved chimneys were in six different communities. In all but two cases, preservation took place in the fall, after Chimney Swifts had left the area; the other two were repaired in early spring before Chimney Swifts arrived. Eight sites were preserved after the 2016 season and their efficacy cannot be gauged. * The other six, which were all repaired, were all occupied following the repairs, including the two repaired in the spring. The average number of birds using the chimney after repair was $5.5+1.03$ ( $n=19$ observations at six chimneys) although the modal count was two. The maximum was 19. Only a few chimneys are monitored by MCSI to assess nesting success. Despite that low effort, young have been documented fledging from two of these six repaired sites.

\section{Discussion}

Our estimates of the number of potential sites available to Chimney Swifts may be positively biased. Many liners are detectable because they extend several centimetres above the bricks but some may not be seen. Screens are usually obvious. Caps may be installed that are undetected. Conversely, flashing installed only to protect the bricks may be mistaken for a cap and a metal or tile insert that is seen from the ground may extend only a short distance into the chimney (negative biases). However, the calculated loss rate of potential sites was virtually identical to that for active sites and the effects of any detection bias must be small.

Habitat losses refer to both active and potential habitat. The value of

*Note added in proof: One of these eight, a nest site, was reoccupied in May 2017 but is not included in the analysis. protecting potential habitat was made obvious by two subsequent events. One small chimney where no entries or exits were recorded was on a small hotel with a second chimney that was used by Chimney Swifts. That known active chimney required repairs and in the course of repairing it in 2016, the cleanout trap of the small chimney was inspected. It contained considerable amounts of Chimney Swift nesting debris and hundreds of dead bees; there was a bees' nest blocking the flue. The debris and nest were removed and the chimney repaired. Whether Chimney Swifts return to this site awaits a future season but the presence of a bee nest may have been the main deterrent to Chimney Swift occupancy.

The second case involves the sudden 'colonization' of one site in Winnipeg. Assiniboine School had been monitored by MCSI since the program's inception in 2007. Prior to 2014, it had been occupied by zero to 10 birds each year. Since then it has housed more than 100 Chimney Swifts each year (Fig. 6), including a nesting pair in 2016, and is currently
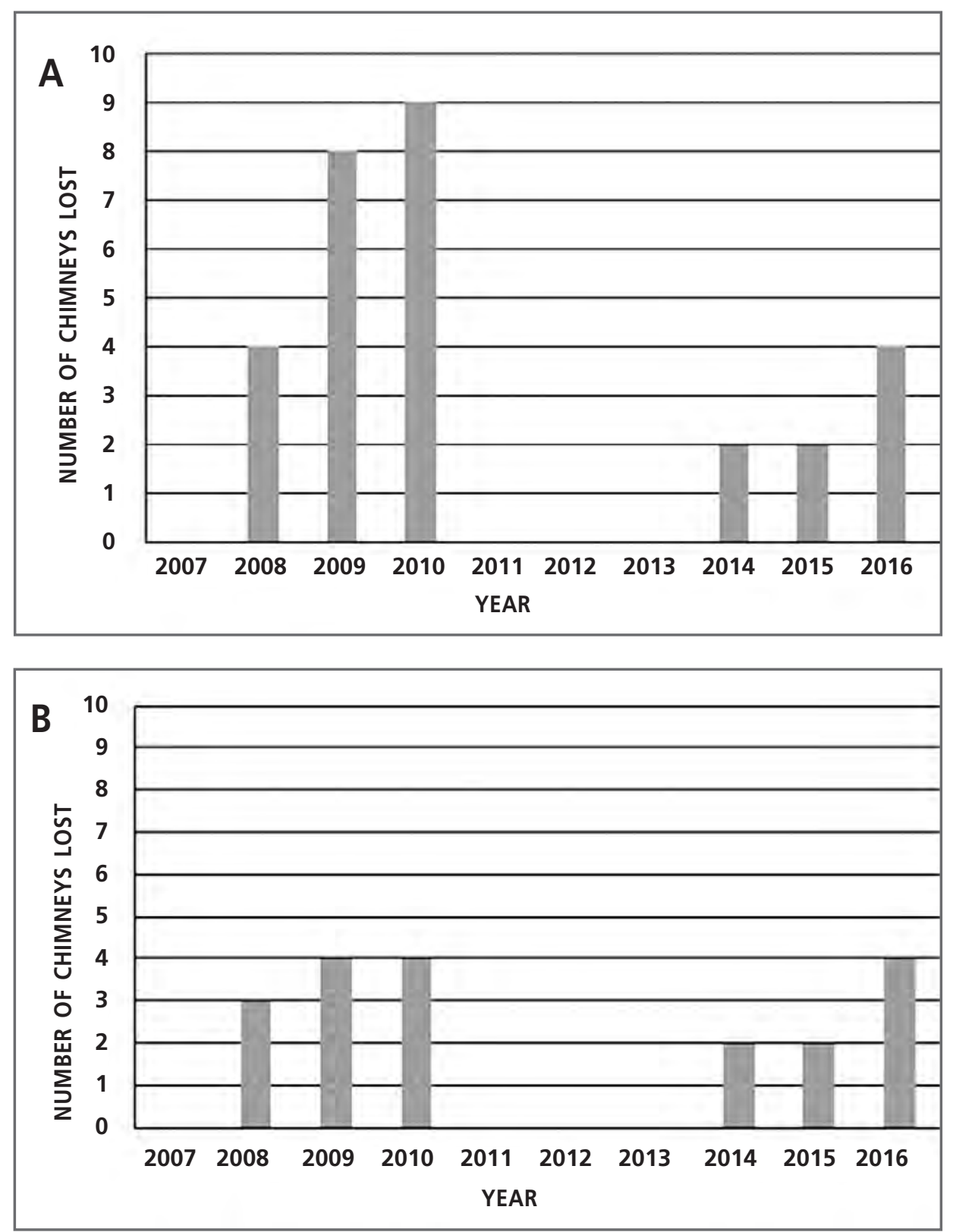

FIGURE 3. Recorded numbers of (A) potential plus active sites and (B) the number of active Chimney Swift sites lost in Manitoba in 2007-2016. Monitoring began in 2007 and recorded losses that year may be negatively biased. 
the largest known roost in Manitoba. This influx of birds also indicates our estimate of habitat loss is negatively biased because the most obvious cause of the sudden arrival of so many birds is displacement from some other roost or roosts. Based on local reproductive success a population explosion producing 100 new birds is implausible. , $^{2}$

Our monitors recorded no losses of known sites in the years 2011, 2012 and 2013 (Fig. 3) which appeared unrelated to monitoring effort
(Fig. 2). We are at a loss to explain this as anything but a reflection of the vagaries of the chimney repair business. There are too few data for detailed spatio-temporal analysis but 18 of the 20 lost sites in Winnipeg were in a part of the city settled largely before 1930 and all within a few kilometres of each other. Some sites are close enough that seeing repairs at one site could influence the owners of nearby sites.

MCSI's chimney preservation activities began in 2009 but most

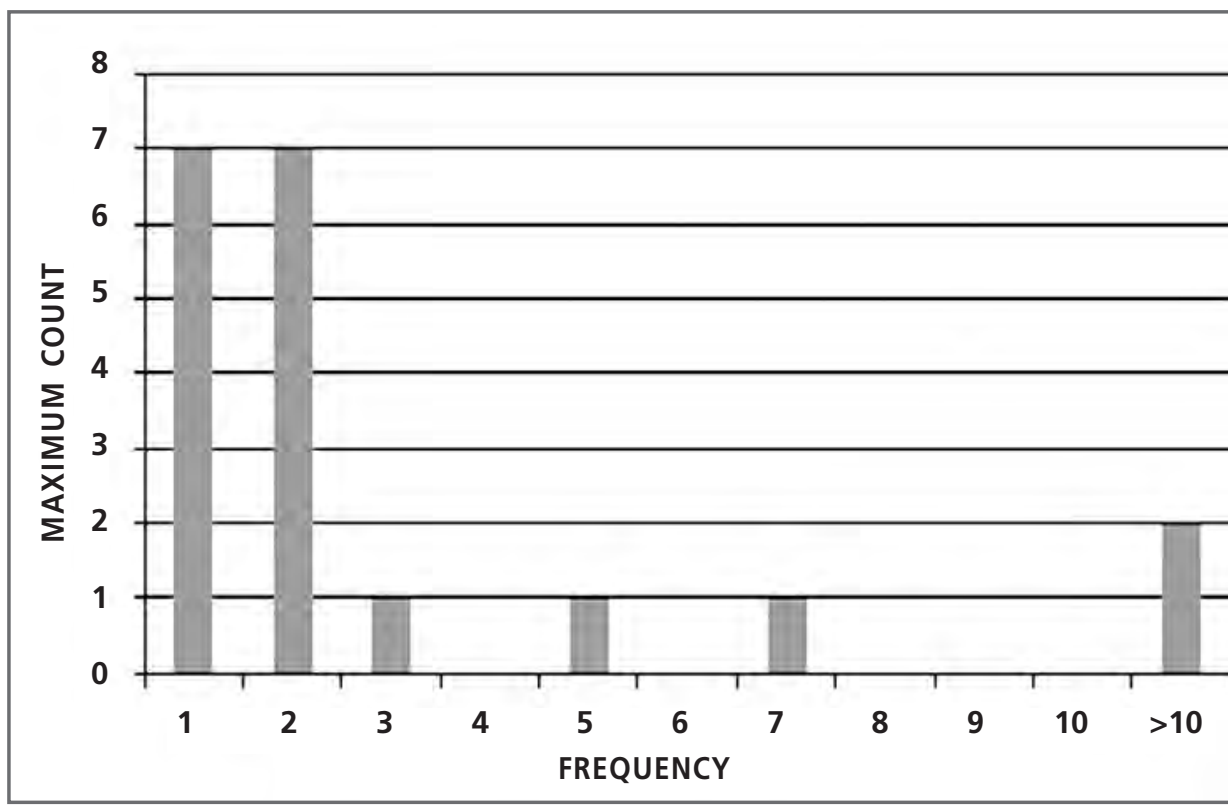

FIGURE 4. Maximum number of Chimney Swifts recorded entering chimneys which were subsequently closed.

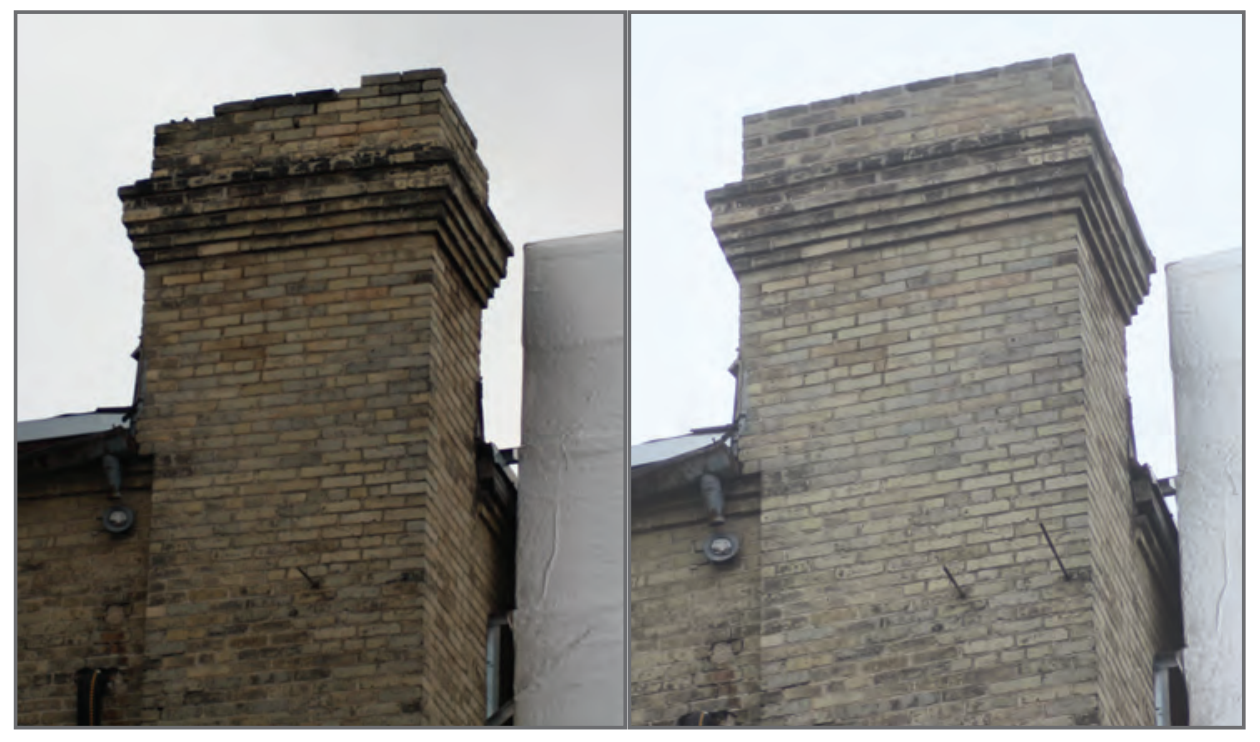

FIGURE 5. A chimney repaired in the Manitoba Chimney Swift Initiative preservation program. Before (left) lost bricks and failing joints are apparent before the repairs (right). (Photo copyright - TF Poole, 2016)

have taken place since 2015. Over the decade, 15 chimneys were slated for closure or demolition. Had these chimneys been added to the realized losses, 44 sites (22\% over the 10 years) would have been lost rather than 29 sites ( $14.5 \%$ over 10 years).

MCSI has shown that chimneys designated for closure can be saved and it follows that some lost chimney habitat may be restored. Capped or screened chimneys can be reopened with a reasonable expectation that the Chimney Swifts would return. The chimney at St. Avila School in Winnipeg was used by a pair of Chimney Swifts in 2009 and 2011 (not in 2010) then capped after the 2011 season, unbeknownst to MCSI, which continued to monitor the site. The cap blew off in a storm before the 2016 season. The site was not monitored in 2015 but supported a nesting pair in 2016. Officials have agreed not to recap this chimney and preserve it as Chimney Swift habitat.

We found that both actively used chimneys and potential sites for which MCSI had no evidence of occupancy were being rendered unavailable to chimneys swifts at a rate of about 1.5\% per year between 2007 and 2016. COSEWIC indicated about $35 \%$ of parish chimneys in Québec were not available but did not provide a temporal reference. ${ }^{6}$ That report used 1950 as the nominal start of conversions to electric heat and chimney obsolescence. Using 1950 to 2007 as the time frame for $35 \%$ loss provides an estimate of about $0.6 \%$ per year. We could find no other estimate of the rate of annual habitat loss in the literature.

But is loss of habitat at 1.5\% ( $2.2 \%$ without preservation actions) significant to the population of Chimney Swifts in Manitoba? Overall, information on population trends for Chimney Swifts is imprecise and often contradictory and data for Manitoba are sparse. The best data 
may be the Breeding Bird Survey data for the Prairie Pothole Bird Conservation Region, tabulated in the United States Fish and Wildlife Service (USFWS) database. ${ }^{7}$ The USFWS data for this region are considered only moderately reliable and suggest a population decline of $1.66 \%$ per year between 2005 and 2015, but the $95 \%$ credibility interval $(-5.90$ to 2.34) includes zero so the trend is not statistically significant. ${ }^{7}$ The large credibility interval on the USFWS estimate does not mean there has been no decline; only that the data are insufficient to detect a change.

While it is not possible to link the annual rate of chimney losses to the equivocal and perhaps not significant changes in population, it is reasonable to suggest that closure of chimneys may be a limiting factor in Chimney Swift recovery. However, Fitzgerald et al. noted that over $75 \%$ of potentially suitable Chimney Swift sites were not occupied in southern Ontario. ${ }^{3}$ Of the 191 chimneys monitored by MCSI, 57 (29.8\%) have not been seen to house Chimney Swifts (sampling rate is $13.7 \%$ of 519 chimney-years, adjusted for lost chimneys). Moreover, three large roost sites in Manitoba have housed large numbers of Chimney Swifts after nesting had started. There appears to be a critical threshold for nesting success in southern Manitoba; no Chimney Swifts that started nest building after June 4 were successful. ${ }^{5}$ Observations on June 6, 2015 and 2016 , that is after the threshold for nesting success, indicated that $83 \%$ and $75 \%$ of birds counted (281 and 194 respectively) were in three large roosts (MCSI unpublished data). Large numbers of Chimney Swifts remain in these roosts through the summer e.g., up to $~ 80$ birds in July of 2014-2016. In Manitoba, the proportion of nonbreeding birds is much higher than the $40 \%$ reported for Québec and agrees with Fitzgerald et al.'s conclusion that other factors are at play when there are numerous empty chimneys and large numbers of non-breeding birds. 3,6

\section{Acknowledgements}

We appreciate the indefatigable efforts of MCSI volunteers, especially those who steadfastly collected valid-zero data points, over the decade. Their dedication made this

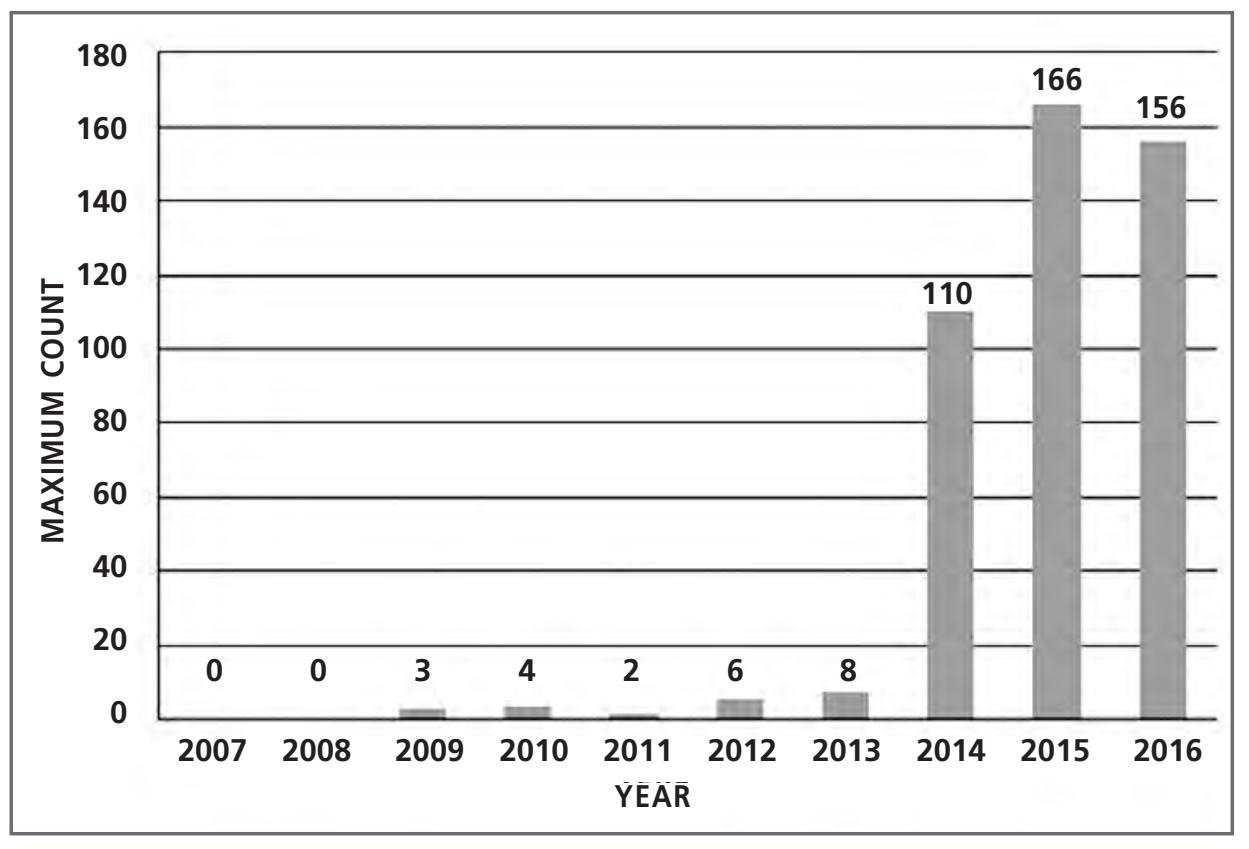

FIGURE 6. Maximum counts of Chimney Swifts entering Assiniboine School in Winnipeg in the roosting hour (30 min before sunset to 30 min after sunset) in the years 2007-2016. Numbers above the bars are the counts. analysis possible. All authors are members of the Manitoba Chimney Swift Initiative Steering Committee and we thank the other Steering Committee members for their ongoing support. We appreciate the assistance of the editor, A. McLeod, and an anonymous reviewer in getting this paper published. MCSI operates under the umbrella of Nature Manitoba. We greatly appreciate DM Lavigne making his photograph of a flying Chimney Swift available to us. Funding was provided to MCSI for chimney repair and restoration by Environment Canada's EcoAction (2009 and 2010), Environmental Damages Fund (2014-2017) and Habitat Stewardship Program (2016 and 2017) and a private donation.

1.SARA (Species at Risk Act) (2017) http:// www.registrelep-sararegistry.gc.ca/species/ speciesDetails_e.cfm?sid=951 (accessed Feb. 20, 2017).

2.Manitoba Government (2017) http:// www.gov.mb.ca/sd/wildlife/sar/sarlist.html (accessed Feb. 26, 2017).

3. Fitzgerald TM, van Stam E, Nocera JJ, Badzinski DS (2014) Loss of nesting sites is not a primary factor limiting northern Chimney Swift populations. Popul. Ecol. 56:507-512. DOI 10.1007/s10144-0140433-6

4. Stewart BE, Stewart REA (2010) Nest site use and breeding success of Chimney Swifts in St. Adolphe, MB, 2007-2009. Blue Jay 68:124-132.

5. Stewart BE, Stewart REA (2013) Nest site use, breeding success, and reproductive rates of Chimney Swifts in St. Adolphe, MB, 2010-2013. Blue Jay 71:166-182.

6. COSEWIC (2007) COSEWIC assessment and status report on the Chimney Swift Chaetura pelagica in Canada. Committee on the Status of Endangered Wildlife in Canada. Ottawa. vii + 49 pp.

7. USFWS (2017) https://www.mbr-pwrc. usgs.gov/cgi-bin/atlasa15.pl?04230\&1\&15 \&csrfmiddlewaretoken=3YKakk7LxT2ki6N Spl4mstudYCqdW02C (accessed March 2, 2017). 